\title{
A DIMENSÃO DISCURSIVA DA COGNIÇÃO OU A DIMENSÃO COGNITIVA DO DISCURSO
}

\author{
FERNANDA MUSSALIM \\ $(\mathrm{UFU} / \mathrm{CNPQ})^{1}$
}

\begin{abstract}
RESUMO: Neste ensaio, pretendo me debruçar sobre aspectos discursivos da produção da linguagem - tanto do ponto de vista teórico, quanto analítico - a fim de demonstrar a produtividade da proposta da Neurolinguística de tradição discursiva (ND), postulada/praticada por Maria Irma Hadler Coudry. Mais especificamente, buscarei demonstrar, a partir da consideração de um dado que compõe o Banco de Dados em Neurolinguística (BDN), como a proposta da ND, que assume os processos discursivos/ interacionais como princípio teórico-metodológico de base, pode lançar luzes sobre conceitos oriundos do Sociocognitivismo, mais especificamente, para os propósitos deste texto, sobre o conceito de cognição distribuída (FLOR, HUTCHINS, 1991). Observar o trabalho realizado no Centro de Convivência de Afásicos (CCA), criado por Coudry em 1989 no Instituto de Estudos da Linguagem (IEL-UNICAMP), possibilitou-me perceber a necessidade de propor, para a concepção de cognição distribuída, a incorporação da noção de dispositivo comunicacional (MAINGUENEAU, 2002, 2006, 2015) - ao menos quando o objetivo central da pesquisa é tratar questões de linguagem, como é o caso do trabalho com os afásicos.
\end{abstract}

Palavras-chave: Neurolinguística Discursiva; cognição distribuída; dispositivo comunicacional; afasia.

ABSTRACT: In this essay, I intend to address the discursive aspects of language production, both theoretically and analytically, so as to demonstrate the productivity of Discursive Neurolinguistics proposal (DN), postulated/practiced by Maria Irma Hadler Coudry. More specifically, drawing from the analysis of a specific data gathered in the Neurolinguistics Database (IEL-UNICAMP), I intend to demonstrate how DN proposal - which assumes discursive/interactional processes as a theoreticalmethodological baseline principle - can shine a light on concepts deriving from sociocognitivism, specially for the purposes addressed on this text regarding the concept of distributed cognition (FLOR, HUTCHINS, 1991). By observing the work carried out at the Community Center for Aphasics (CCA), created by Coudry in 1989 at the Institute of Language Studies (IEL-UNICAMP), I was able to understand the need to propose the incorporation of the notion of communicational device (MAINGUENEAU, 2002, 2006, 2015) for the conception of distributed cognition - at least when the main purpose of the research is to deal with language issues, as in the case of the work with aphasic people.

Keywords: Discursive Neurolinguistics; distributed cognition; communicational device; aphasia.

${ }^{1}$ Docente do Instituto de Letras e Linguística da Universidade Federal de Uberlândia. Honorary Visitor Fellow na Universidade de Leicester, Inglaterra (01/12/2017 a 30/11/2018). Bolsista PQ pelo CNPq. E-mail: fmussalim@gmail.com. Homepage: www.fernandamussalim.com.br 


\section{CONSIDERAÇÕES INICIAIS}

Os trabalhos teórico-metodológicos de Maria Irma Hadler Coudry em Neurolinguística, que vêm sendo desenvolvidos no Instituto de Estudos da Linguagem (IEL) da Universidade Estadual de Campinas (UNICAMP) há mais de três décadas, fundamentam-se em uma orientação discursiva que tem se mostrado extremamente produtiva não apenas na abordagem de dados de linguagem de sujeitos afásicos, mas também no acompanhamento longitudinal desses sujeitos. Neste ensaio, pretendo me debruçar sobre aspectos discursivos da produção da linguagem - tanto do ponto de vista teórico, quanto analítico - a fim de demonstrar a produtividade da proposta da Neurolinguística de tradição discursiva (ND), postulada/praticada por Maria Irma Hadler Coudry. Mais especificamente, buscarei demonstrar, a partir da consideração de um dado que compõe o Banco de Dados em Neurolinguística (BDN), como a proposta da ND, que assume os processos discursivos/interacionais como princípio teórico-metodológico de base, pode lançar luzes sobre conceitos oriundos do Sociocognitivismo, mais especificamente, para os propósitos deste texto, sobre o conceito de cognição distribuída (FLOR, HUTCHINS, 1991). Observar o trabalho realizado no Centro de Convivência de Afásicos (CCA)², criado por Coudry em 1989 no Instituto de Estudos da Linguagem (IEL-UNICAMP), possibilitou-me perceber a necessidade de propor, para a concepção de cognição distribuída, a incorporação da noção de dispositivo comunicacional (MAINGUENEAU, [1998] 2002, [2005] 2006, [2014] 2015) - ao menos quando o objetivo central da pesquisa é tratar questões de linguagem, como é o caso do trabalho com os afásicos.

Iniciarei o texto com um percurso teórico que me conduziu às portas da Neurolinguística, campo que tenho tido o privilégio de percorrer sob a supervisão de Coudry, em um pós-doutoramento sênior realizado no IEL-UNICAMP ${ }^{3}$, com estágio no Centro de Neurociências, Psicologia e Comportamento da Universidade de Leicester ${ }^{4}$, Inglaterra (Reino Unido), sob a supervisão de Briony Pulford. Mais especificamente, na seção a seguir, apresentarei o percurso-reflexão que contextualiza o modo como concebo o lugar da dimensão cognitiva na teoria do discurso de tradição francesa (PAVEAU, [2006] 2013), a saber, como um tipo específico de anterioridade discursiva.

Em seguida, a partir de uma concepção específica de sociocognição - a cognição distribuída (HUTCHINS, 1990, 1995a, 1995b, 2002 e HUTCHINS, KLAUSEN, 1996) - e do conceito de dispositivo comunicacional de Dominique Maingueneau ([1998] 2002, [2005] 2006, [2014] 2015), farei uma releitura de um dado que compõe o Banco de Dados em Neurolinguística (BDN) - construído, em grande parte, a partir do trabalho de pesquisadores do grupo de pesquisa

${ }^{2}$ No CCA, os pesquisadores desenvolvem práticas com a linguagem, que são discursivamente orientadas e integradas na avaliação e acompanhamento longitudinal de sujeitos afásicos.

${ }^{3}$ Agradeço ao CNPq o financiamento concedido para pós-doutorado sênior no país - PDS (Proc. 108541/2017-7), no período de 01/08/2017 a 31/07/2018.

${ }^{4}$ Agradeço ao $\mathrm{CNPq}$ o financiamento concedido para estágio de pós-doutorado sênior no exterior - ESN (Proc. 203761/2017-0), no período de 01/12/2017 a 28/02/2018. 
Neurolinguística Discursiva: afasia e infância (liderado por Coudry e certificado pelo CNPq), junto ao Centro de Convivência de Afásicos (CCA) -, enfatizando a fecundidade da relação discurso/(socio)cognição, tão bem sedimentada pela Neurolinguística de tradição discursiva (ND) proposta por Coudry ([1986] 1988 e outros trabalhos) e desenvolvida por seu grupo de pesquisa.

\section{SOBRE AS ANTERIORIDADES DO DISCURSO}

A Análise do discurso (AD), especialmente a de vertente francesa, tem se debruçado, desde a sua fundação, sobre a problemática das anterioridades ou, mais especificamente, sobre a problemática dos discursos, enunciados e sentidos produzidos numa espacialidade e/ou temporalidade anterior à produção de um discurso em questão. Conceitos como memória discursiva, interdiscurso, préconstruído e discurso transverso - dos quais diferentes autores se ocuparam testemunham o papel central que essa problemática tem no campo da AD.

$\mathrm{O}$ conceito de formação discursiva (FD) é central para se compreender a formulação desses quatro conceitos que, de alguma maneira, decorrem do trabalho teórico-analítico realizado pelos analistas do discurso a partir dessa noção. Em Arqueologia do saber, Michel Foucault define discurso como um número limitado de enunciados para os quais se pode definir um conjunto de condições de existência, ou seja, um sistema de formação. $\mathrm{O}$ intuito do autor é descrever esse sistema de formação, isto é, a formação discursiva, definida como "um conjunto de regras anônimas, históricas, sempre determinadas no tempo e no espaço que definiram em uma época dada, e para uma área social, econômica, geográfica ou linguística dada, as condições de exercício da função enunciativa" (FOUCAULT, [1969] 2004, p. 133). Assumindo o enunciado como unidade de análise, Foucault busca definir as formações discursivas a partir de suas regularidades (e mudanças) e, para tanto, delineia quatro hipóteses - relacionadas à formação dos objetos, às modalidades de enunciação, à formação dos conceitos e à formação das estratégias - que fundamentam a arqueologia que propõe enquanto método de análise dos discursos.

A problemática da memória, nesta proposta de Foucault, aparece vinculada à hipótese relacionada à formação dos conceitos. $\mathrm{O}$ autor refuta a ideia de que a unidade dos discursos se funda na persistência e permanência de determinados conceitos e defende que o reconhecimento dessa unidade decorre da descrição da organização do campo em que os enunciados aparecem e circulam, isto é, da descrição de como esses enunciados se sucedem e de quais são suas formas de subsistência. A análise das formas de subsistência dos enunciados implica a consideração do:

i) campo de presença: todos os enunciados já formulados em alguma parte e que são retomados em um discurso, a título de pressuposto necessário, verdade admitida, raciocínio fundado, bem como todos os enunciados discutidos, criticados, julgados, rejeitados, excluídos; 
ii) campo de concomitância: enunciados que pertencem a tipos de discurso diversos e/ou que se referem a domínios de objetos inteiramente diferentes, mas que atuam entre os enunciados estudados, valendo como confirmação lógica, princípio geral, modelos transferíveis a outros conteúdos etc.;

iii) domínio de memória: enunciados que não são mais admitidos, nem discutidos e que, por isso, não definem mais nem um corpo de verdades, nem um domínio de validade, mas em relação aos quais são estabelecidos laços de gênese, filiação, transformação, continuidade ou descontinuidade histórica.

A consideração tanto dos enunciados já formulados em alguma parte e retomados em um discurso (a título de pressuposto necessário, verdade admitida, raciocínio fundado), quanto dos enunciados que não definem mais nem um corpo de verdades, mas em relação aos quais são estabelecidos laços de gênese, filiação, transformação, continuidade ou descontinuidade histórica, coloca em cena a problemática da memória discursiva - que tem naturezas distintas, caso se trate do campo de presença (seria possível relacionar a esse campo as noções de pré-construído e discurso transverso), ou do domínio da memória (que, em alguns aspectos, aproxima-se do que, muito recentemente, Marie-Anne Paveau denominou de pré-discursos) $)^{6}$. Por sua vez, a consideração dos enunciados que pertencem a tipos de discurso diversos e/ou que se referem a domínios de objetos inteiramente diferentes, mas que atuam entre os enunciados estudados (campo de concomitância), parece relacionar-se, em alguma medida, a certas facetas do funcionamento do interdiscurso ${ }^{7}$.

Jean-Jacques Courtine, em Análise do discurso político: o discurso comunista endereçado aos cristãos, incorpora, a partir do quadro teórico de uma AD filiada ao pensamento althusseriano, a noção de memória discursiva na análise do discurso político. Não obstante, considera essa noção subjacente à análise das formações discursivas realizada por Foucault em Arqueologia do saber, na medida em que a relaciona ao processo de retomada de enunciados, que são repetidos, refutados, transformados, denegados. Afirma ainda que a noção de memória discursiva em AD coloca em jogo a articulação dessa disciplina com formas contemporâneas da pesquisa histórica, uma vez que atualiza certas preocupações com relação à pluralidade dos tempos. De acordo com o autor,

A noção de memória discursiva diz respeito à existência histórica do enunciado no interior de práticas regradas por aparelhos ideológicos; ela visa o que Foucault $(1971$, p. 24) levanta a propósito dos textos religiosos, jurídicos, literários, científicos, "discursos que originam um certo número de novos atos, de palavras que os retomam, os transformam ou falam deles, enfim, os discursos que indefinidamente, para além de sua formulação, são ditos, permanecem ditos e estão ainda a dizer". (COURTINE, [1981] 2009, p. 105-106; grifo do autor)

\footnotetext{
${ }^{5}$ Cf. Henry ([1975] 1990) e Pêcheux ([1975] 1988).

${ }^{6}$ Cf. Paveau ([2006] 2013).

${ }^{7}$ Cf. Maingueneau ([1984] 2005).
} 
A consideração de uma memória discursiva, esclarece Courtine ([1981] 2009, p. 106), remete a questões como "do que nos lembramos e como nos lembramos, na luta ideológica, do que convém dizer e não dizer, a partir de uma determinada posição em uma conjuntura dada"? Ou ainda: como o trabalho de uma memória coletiva permite, no interior de uma FD, a lembrança, a repetição, a refutação e também o esquecimento de enunciados?

Em relação ao modo material de existência de uma memória discursiva em uma formação discursiva, Courtine ([1981] 2009, p.6) afirma que é na relação entre interdiscurso e intradiscurso que se manifesta o processo por meio do qual uma "formulação-origem retorna na atualidade de uma "conjuntura discursiva". Essa afirmação traz à tona a problemática do pré-construído, noção elaborada por Paul Henry ([1975] 1990) e desenvolvida por Michel Pêcheux ([1975] 1988).

O pré-construído diz respeito a uma construção anterior, exterior e independente, por oposição ao que é construído na enunciação. Nesse sentido, ele marca um descompasso entre o interdiscurso, lugar em que é construído, e o intradiscurso, espaço de enunciação de um sujeito. O interdiscurso fornece os objetos dos quais a enunciação de uma sequência discursiva se apropria ${ }^{8}$, ao mesmo tempo em que atravessa essa enunciação e conecta entre si esses objetos, funcionando como um discurso transverso, que regula o modo de dação dos objetos dos quais o discurso fala, bem como o modo como tais objetos se articulam no "fio do discurso" . Nessa perspectiva, o intradiscurso de uma sequência discursiva configura-se como um efeito do interdiscurso sobre o intradiscurso.

Sob o escopo da noção de formação discursiva, portanto, a relação entre interdiscurso e intradiscurso faz intervir a memória discursiva, operacionalizada por meio das categorias de pré-construído e discurso transverso.

Nesse quadro teórico de vertente althusseriana (ao qual se filiaram autores como Paul Henry, Michel Pêcheux e Jean-Jacques Courtine), o interdiscurso configura-se como uma anterioridade, não apenas por ser o lugar de construção do pré-construído e do discurso transverso, mas também pelo fato de toda formação discursiva ser dominada por ele, ou seja, estar submetida a um conjunto estruturado das formações discursivas, a um "todo complexo com dominante das formações discursivas, intricado no complexo das formações ideológicas” (PÊCHEUX, ([1975] 1988, p. 162).

Nas formulações de Dominique Maingueneau ([1984] 2005), o postulado do primado do interdiscurso sobre o discurso também configura o interdiscurso, ao menos de certa perspectiva, como uma anterioridade. De acordo como esse postulado, o que há, a princípio, é o interdiscurso (um conjunto de formações

${ }^{8}$ Isso ocorre, por exemplo, da seguinte maneira: um elemento do interdiscurso nominaliza-se e inscreve-se no intradiscurso como pré-construido, como se esse elemento já se encontrasse ali. É nesse sentido que a noção de pré-construido pode ser considerada uma reformulação das teorias da pressuposição de Oswald Ducrot ([1972] 1977).

${ }^{9} \mathrm{O}$ traço do interdiscurso enquanto discurso transverso no intradiscurso aparece como a lembrança lateral de um saber que vem sob a modalidade de um "como se sabe", "como se pode ver". $\mathrm{O}$ estudo do funcionamento do interdiscurso como discurso transverso se deu, fundamentalmente, a partir de trabalhos concernentes às orações relativas. 
discursivas em relação), de modo que a identidade de cada FD não está dada a priori, mas se constitui de maneira regulada no interior de um interdiscurso. Ao mesmo tempo, entretanto, esse mesmo postulado pode ser compreendido como uma formulação que privilegia a ordem das concomitâncias (e, nesse sentido, aproxima-se, ao menos em parte, da noção de campo de concomitância, formulada por Foucault), se considerarmos, por exemplo, o processo de constitutividade mútua das formações discursivas no campo discursivo ${ }^{10}$ : a identidade de uma FD vai se constituindo ao mesmo tempo em que se vai delimitando suas fronteiras em relação a outra(s) FD(s). Nesse caso, em que se considera a constitutividade mútua das FDs, num recorte espaço-temporal específico, privilegiam-se as relações de concomitância.

Recentemente, Marie-Anne Paveau, em seu livro Os pré-discursos: sentido, memória e cognição ([2006] 2013), postulou, para o campo da AD, mais uma categoria relacionada à problemática das anterioridades: o pré-discurso. Em linhas gerais, a autora define os pré-discursos como "um conjunto de quadros pré-discursivos coletivos (saberes, crenças, práticas) que dão instruções para a produção e para a interpretação do sentido no discurso" (PAVEAU, [2006] 2013, p. 130). Os quadros pré-discursivos coletivos são partilhados coletivamente e apropriados individualmente - fenômeno que pode ser mais bem explicado com base no pressuposto da intersubjetividade, fundamental para se compreender o fato de que os pré-discursos, anteriores coletivos de todos os locutores de um grupo ou de uma comunidade, são apropriados pelos locutores individuais que mantêm a ilusão de construir versões individuais e originais do mundo. Além disso, a autora esclarece que os pré-discursos têm uma realidade imaterial, uma vez que não se inscrevem diretamente na materialidade discursiva, apesar de nela imprimirem "marcas" indiretas. Nesse sentido, eles não são formuláveis, nem traduzíveis no discurso, mas identificáveis pelos traços de sua presença. De acordo com Paveau, os pré-discursos dizem respeito a dados de natureza mais social e cultural do que a dados de natureza ideológica e política, aplicando-se, por isso, a todos os tipos de discurso, desde os mais ordinários e pouco controlados, até os mais elaborados e controlados.

O foco da abordagem de Paveau ([2006] 2013, p. 12) recai sobre o que ela chama de "determinações pré-linguísticas", isto é, recai sobre dados anteriores à formulação da linguagem. Sua pretensão é debruçar-se sobre o problema da "caixa preta" das informações prévias "que informa os discursos e, sobretudo, sobre o ponto de articulação entre esses dados anteriores e as produções verbais". A autora admite, pois, que os discursos se apoiam em saberes e crenças partilhadas, mas considera que, da perspectiva da Análise do Discurso (mirante do qual faz

${ }^{10}$ Maingueneau ([1984] 2005) propõe que se considere o interdiscurso a partir da tríade universo discursivo, campo discursivo e espaço discursivo. A noção de universo discursivo diz respeito ao conjunto de formações discursivas de todos os tipos, que interagem em uma conjuntura dada. O campo discursivo deve ser compreendido como sendo um conjunto de formações discursivas, com mesma função social, que se divergem, entretanto, quanto ao modo pelo qual essa função deve ser preenchida. O espaço discursivo deve ser compreendido como um subconjunto de formações discursivas cuja relação o analista julga pertinente considerar para seu propósito. 
sua proposta), a natureza desse apoio ainda é pouco esclarecida. O termo "prédiscurso", portanto, não é imotivado; diz respeito a um tipo de anterioridade discursiva, que opera na negociação da partilha, da transmissão e da circulação do sentido nos grupos sociais: "o locutor dispõe de informações prévias, tratadas e estocadas antes de produzir discursos", o que não impede que "essas informações sejam também construídas e negociadas no discurso, enquanto apresentadas como pré-discursivas" (PAVEAU, [2006] 2013, p. 20).

O conceito de pré-discurso dota a Análise do Discurso de uma dimensão cognitiva, compreendida por Paveau ([2006] 2013, p. 9) como "processos de construção de conhecimentos e sua configuração no discurso a partir de dados recebidos pelos sentidos, pela memória e pelas relações sociais". Suas referências teóricas, nas Ciências Cognitivas, inscrevem-se na linha sociocultural, que concebe a cognição como um fenômeno discursivo, situado em contextos históricos e sociais. Mais especificamente, a autora se filia à corrente da cognição distribuída, que repousa sobre o pressuposto de que "a cognição deixa, por assim dizer, a 'cabeça' do indivíduo, para se tornar um fenômeno social e distribuído" (BISCHOFSBERGER, 2002, apud PAVEAU, ([2006] 2013, p, 9). Foi em função dessas formulações de Paveau que meu percurso de pesquisa me conduziu às portas da Neurolinguística de tradição discursiva postulada/praticada por Coudry e seu grupo.

A leitura desse livro (PAVEAU [2006] 2013) ${ }^{11}$ fez-me interessar por uma problemática específica relacionada às produções discursivas, a saber, a da natureza e da dimensão da competência discursiva, definida por Maingueneau ([1984] 2005) como sendo a capacidade de um enunciador de reconhecer enunciados como pertencentes a sua própria formação discursiva, bem como de produzir um número ilimitado de enunciados inéditos pertencentes a essa formação discursiva. Considerando o conceito de pré-discurso postulado por Paveau, parecia-me incontornável que a noção de competência discursiva deveria ser reformulada/ ampliada, a fim de que pudesse vir a incorporar um outro tipo de capacidade do enunciador, a saber, a de operar a partir de quadros pré-discursivos coletivos, que têm um papel "instrucional" para a produção e interpretação dos discursos. A competência discursiva, portanto, passaria a contemplar, minimamente, aspectos de duas naturezas: ideológica e cognitiva ${ }^{12}$.

No Centro de Convivência de Afásicos (CCA), tenho tido a possibilidade de acompanhar os debates teóricos, os modos de intervenção e os resultados de práticas terapêuticas de pesquisadores que desenvolvem trabalho na área da Neurolinguística de tradição discursiva. O viés discursivo na condução de suas pesquisas sobre sujeitos cérebro-lesados define um modo específico de conceber

${ }^{11}$ Em 2014, em um dos Seminários de Pesquisa do Centro de Pesquisa FEsTA - Fórmulas e estereótipos: Teoria e Análise - vinculado ao IEL/UNICAMP, coordenado por Sírio Possenti e do qual vários pesquisadores de diferentes universidades brasileiras fazem parte -, tive a oportunidade de entrar em contato com a obra de Marie-Anne Paveau, recém traduzida no Brasil.

${ }^{12}$ Essa hipótese sustenta o projeto de pesquisa "A problemática da anterioridade discursiva em Análise do Discurso: em pauta a dimensão cognitiva da teoria do discurso", desenvolvido (2017-2018) sob os auspícios do CNPq e a supervisão de Coudry. 
os processos cognitivos, pautado, sobretudo, na hipótese não localizacionista do cérebro, uma vez que o compreendem como um sistema funcional que responde a processos interacionais. Esse espaço de pesquisa e de acompanhamento longitudinal de afásicos vem possibilitando um diálogo fecundo com o postulado da cognição distribuída; mais que isso, tem me permitido refletir sobre a necessidade de imprimir a esse postulado um viés que possibilite um tratamento mais adequado a questões de linguagem, como procurarei demonstrar, na seção a seguir.

Iniciarei a seção apresentando, em linhas gerais, o conceito de cognição distribuída; em seguida, apresentarei um dado que compõe o BDN, buscando dar visibilidade ao modo como a condução do trabalho realizado com sujeitos afásicos no CCA pode lançar luzes sobre as teorizações em torno do postulado da cognição distribuída; por fim, proporei, a partir da concepção de dispositivo comunicacional (MAINGUENEAU, [1998] 2002, [2005] 2006, [2014] 2015), uma releitura do conceito de cognição distribuída.

\section{RELEITURAS}

Conforme afirma Paveau ([2006] 2013, p. 135), a cognição distribuída é "produto de interações entre os sujeitos falantes e, sobretudo, eu diria, entre os sujeitos e seu ambiente natural, social, tecnológico, etc.". Em outras palavras, a cognição distribuída busca compreender como a inteligência se manifesta no nível sistêmico - e não apenas no nível cognitivo individual -, mediante o estudo da representação do conhecimento nas mentes dos indivíduos e sua propagação entre indivíduos e artefatos (FLOR, HUTCHINS, 1991). Tal abordagem defende que a cognição, além de ser um fenômeno distribuído entre dois ou mais indivíduos, também o é entre indivíduos, ambientes e artefatos que se relacionam. Esses artefatos (cognitivos) consistem em dispositivos utilizados pelos humanos em suas atividades para aprimorar ou melhorar a cognição e o desempenho (NORMAN, 1991; HUTCHINS, 2002).

Os fundamentos da Cognição Distribuída foram consolidados por Edwin Hutchins na década de 1990, a partir de sucessivos estudos sobre sua aplicação na análise do processo de navegação em navios (HUTCHINS, 1990, 1995a) e da distribuição de processos cognitivos na operação de aeronaves (HUTCHINS, 1995b; HUTCHINS, KLAUSEN, 1996). Suas origens, entretanto, são rastreadas por Cole e Engeström (1993) desde os achados de Lev Vygotsky, Alexander Luria, Alexei Leontiev, Clifford Geertz (e outros autores, para os quais a atividade mental se inter-relaciona com aspectos físicos, sociais e culturais do contexto do indivíduo, sendo os processos cognitivos distribuídos entre os componentes de um grupo cujas ações visam a um objetivo comum.

Na concepção de cognição distribuída, a noção de interação (entre sujeitos; entre sujeitos e artefatos) é central. Será, pois, considerando isso, que gostaria de abordar (da perspectiva dessa concepção) o trabalho realizado no CCA.

Coudry apresenta um dado do sujeito afásico GF, em sua tentativa de escrever e ler a palavra "exclamou" que, conforme analisa, apresenta lugares de 
complexidade para ser escrita, como sílaba complexa, ortografia e representação nasal (COUDRY 2016; COUDRY 2018 ${ }^{13}$; COUDRY \& FREIRE, 2017). A seguir, reproduzo o dado:

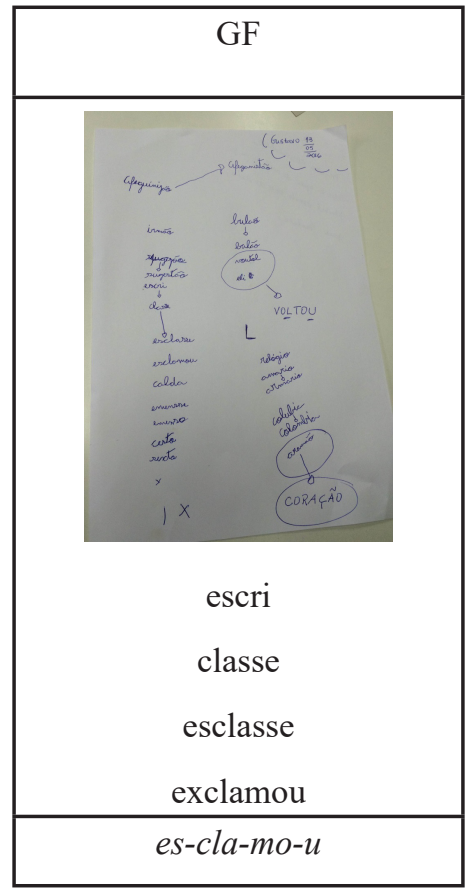

Conforme analisa Coudry (2018), GF ajusta a fala à escrita ao ler em voz alta a palavra exclamou, a fim de dar relevo ao som final $u$, lugar em que hesita na escrita, pois, como muitos falantes, não sonoriza, na fala espontânea, a coda silábica. A escrita orienta a fala de GF, que lê es-cla-mo-u, ao invés de es-cla-mou ou de es-cla-mo. Ao mesmo tempo, entretanto, ele se orienta foneticamente - e não ortograficamente - para escrever a palavra (exclamou), uma vez que usa $s$ ao invés de $x$ (que tem várias representações sonoras). Considerando a sequência de tentativas de escrita da palavra exclamou, a autora analisa:

GF, ao escrever "exclamou", se apoia no modo como fala a palavra: escramou, o que resulta na sua primeira tentativa de escrita (escri). Interpelado pela investigadora para dizer uma palavra com a sílaba cla, diz e escreve classe, o que motiva a paragrafia esclasse e, finalmente, escreve exclamou. (COUDRY, 2018)

Do ponto de vista do postulado da cognição distribuída, tem-se aqui a interação entre sujeitos (o sujeito afásico e a pesquisadora) e entre sujeitos e artefatos (o sujeito afásico, a pesquisadora e o artefato, no caso a folha de papel em que são

${ }^{13}$ Cf., neste mesmo volume, Coudry (2018). 
registradas as tentativas de escrita da palavra "exclamou"), tudo confluindo, como um sistema, para um mesmo objetivo comum: escrever a palavra "exclamou".

$\mathrm{O}$ que me ocorreu, entretanto, ao entrar em contato com este tipo de dado - de trabalho com um sujeito afásico em busca de reconstituição de parte da linguagem - é que a noção de artefato referida na formulação de cognição distribuída (por exemplo, um bloco de notas, um computador, etc.) apresenta apenas um viés cognitivo - na medida em que se configura como um "membro" do sistema cognitivo que agrega insumos para que se chegue a um resultado comum, a saber, o aprimoramento da cognição e do desempenho. O viés enunciativo está fora das formulações dessa concepção, apesar de a noção de interação - e de intersubjetividade - ser nodal para essa perspectiva de cognição. Como, entretanto, considerar escrita como artefato, num caso radical como este, em que escrever significa muito mais que tomar notas? O processo de escrever, em um caso como este, diz respeito a vias enunciativas de reconstituição de linguagem. Foi, pois, à luz desse dado, desse tipo de intervenção realizada no CCA, que me ocorreu ser necessária e produtiva a proposição de uma releitura do conceito de artefato à luz de uma teoria enunciativo-discursiva. Foi dessa perspectiva que passei a incorporar, no desenvolvimento de meu projeto junto ao Grupo de Pesquisa de Coudry, o conceito de dispositivo comunicacional (MAINGUENEAU, [1998] 2002, [2005] 2006, [2014] 2015) à teorização da cognição distribuída, com o objetivo de proceder a um tratamento mais adequado de dados de linguagem. Com relação ao conceito de dispositivo, vale alguns esclarecimentos.

A noção de dispositivo implica, ao mesmo tempo, a ideia de "disparo da enunciação" e de coerção. Em relação à primeira ideia, vale esclarecer que compreender o dispositivo enquanto uma instância que dispara a enunciação pressupõe a consideração de que a transmissão do texto não vem depois de sua produção e que suas formas de circulação não vêm depois de sua produção e antes de sua recepção; diferentemente, tudo isso se instaura concomitantemente e de maneira integrada, ao se acionarem certos dispositivos comunicacionais, como os gêneros do discurso e o mídium, que exercem coerções específicas sobre a enunciação - o que nos conduz à segunda ideia, de coerção, que, por sua vez, diz respeito a condicionadores das práticas discursivas de uma sociedade (ou grupo, ou comunidade). Para melhor esclarecer a noção de dispositivo, buscarei especificar um pouco mais em que sentido os gêneros do discurso e os mídiuns se configuram como dispositivos comunicacionais.

Em relação à noção de gênero do discurso, Maingueneau afirma que cada gênero implica uma cena específica que impõe, de maneira integrada e concomitantemente, um modo de inscrição dos sujeitos interlocutores no espaço e no tempo, um suporte material, um modo de circulação, uma finalidade. As condições de enunciação ligadas a cada gênero de discurso correspondem a certas expectativas e antecipações dos interlocutores a respeito de como devem se inscrever discursivamente por meio de certos gêneros. Essas condições de enunciação são formuladas por meio de certas questões que levam em conta o caráter de legitimidade das práticas discursivas: Quais os interlocutores, o lugar e o momento necessários para realizar esse gênero? Quais as condições de/para 
sua circulação? Que normas presidem seu consumo? Nesse sentido, os gêneros do discurso, ao mesmo tempo em que "disparam a enunciação" (fazendo com que se levem em conta, de maneira integrada e concomitante, expectativas e antecipações), realizam coerções (na medida em que impõem aos sujeitos interlocutores um certo modo de inscrição social por meio da linguagem), constituindo-se, portanto, em um dispositivo comunicacional.

No que se refere ao mídium, Maingueneau, na esteira da midiologia proposta por Régis Debray (1991, p. 197), que a define como sendo “o estudo das mediações através das quais "uma ideia se torna força material", propõe que se reintroduza, no estudo do discurso, a consideração dos suportes por sob a impressão e das redes por sob as mensagens, de modo a devolver ao ato discursivo seus materiais. Nesse sentido, entra no horizonte dos estudos do discurso a problemática dos contextos de difusão e circulação da enunciação, dos textos, isto é, de suas formas de existência social - que atuam tanto como expectativas e antecipações (e de maneira integrada a outros níveis de funcionamento da enunciação), quanto como coerções, configurando-se o mídium, também, como um dispositivo comunicacional. Esse tipo de abordagem permite que se deslize, facilmente, do problema do mídium para o dos gêneros do discurso (isto é, para o das configurações de gestão da fala), uma vez que todo gênero do discurso implica um dispositivo material de comunicação.

Partindo, pois, dos aspectos integrativo e coercitivo implicados na noção de dispositivo comunicacional, empreenderei uma releitura do dado do BDN já apresentado, a fim de demonstrar a produtividade da incorporação desse conceito à teorização da cognição distribuída.

Nessa releitura, gostaria de focalizar os processos de interação a partir dos quais se dá esse evento enunciativo, a fim de pôr a funcionar a concepção de cognição distribuída - já ressignificada em função da proposta de inclusão do conceito de dispositivo comunicacional.

Um dos processos interacionais relevantes na consideração desse dado é a interação entre os mídiuns oral e escrito - neste caso, opomos dois mídiuns de transmissão, a saber, as ondas sonoras e os signos gráficos (MAINGUENEAU, [2005] 2006). Essa interação se dá por meio da movimentação do sujeito afásico GF e da investigadora entre os atos de falar e escrever, mas, sobretudo, pelo fato de GF se apoiar ora na fala (escramou) para se expressar na escrita (escri), ora na escrita para se expressar na fala (es-cla-mo-u). Ao mesmo tempo - e de maneira integrada - ocorre a interação entre GF e a investigadora, que interfere em seu processo de escrita da palavra exclamou, sugerindo que ele fale uma palavra com a sílaba cla - e GF responde à interpelação falando e escrevendo "classe", o que lhe permitirá, no momento subsequente, produzir mais uma hipótese sobre a escrita de exclamou: a paragrafia esclasse.

Diante desse dado e de todo o trabalho desenvolvido e supervisionado por Coudry no CCA - que me possibilitaram vislumbrar um refinamento do conceito de cognição distribuída (ao menos quando a problemática central é a questão da linguagem) -, gostaria ainda de apresentar duas questões que julgo pertinentes: i) por que se trata de um dado bom pra se demonstrar que a cognição é distribuída?; 
ii) por que se trata de uma dado que demonstra a produtividade de se incorporar ao conceito de cognição distribuída à noção de dispositivo comunicacional?

Em relação à primeira questão, é importante distinguir entre um mero conjunto de ações, de um lado, e, de outro, um conjunto de ações que constitui um sistema cognitivo distribuído que se organiza a partir de um "procedimento de agregação". No caso considerado, pode-se reconhecer um sistema cognitivo distribuído em funcionamento, uma vez que todas as ações agregam conhecimento para se chegar a um resultado - comum e coletivo -, almejado pelos interlocutores envolvidos: a escrita da palavra exclamou. Trata-se, pois, de um dado bom para se demonstrar o pressuposto da cognição distribuída.

No que se refere à segunda questão, é relevante verificar se os aspectos integrativo e coercitivo implicados na noção de dispositivo comunicacional podem ser reconhecidos no dado considerado. Em relação ao primeiro aspecto, parece-me evidente que todo processo de interação se configura como um evento enunciativo que se desenrola em função de um dispositivo comunicacional que integra, de maneira concomitante, fala, escrita, leitura e, mais que isso, integra esses elementos na/pela enunciação de dois interlocutores. Nesse sentido, não há antes a fala, depois a escrita, em seguida a leitura, posteriormente a interferência de um interlocutor, mas tudo ocorre concomitantemente e de maneira radicalmente integrada. Considerando o segundo aspecto - o caráter coercitivo do dispositivo -, os mídiuns oral e escrito operam com coerções que não são ignoradas no evento enunciativo analisado, uma vez que certas imposições, como, por exemplo, o processo silábico da escrita em português - nítido no modo como GF vai construindo suas hipóteses sobre a escrita da palavra exclamou e no modo como a investigadora interfere nesse processo -, não podem ser contornadas. Ao contrário, é em função delas que um sistema cognitivo distribuído é posto a funcionar.

\section{CONSIDERAÇÕES FINAIS}

A possibilidade de considerar imbricações mais radicais entre abordagens do cérebro/mente e da linguagem tem constituído um espaço produtivo para se tratar de questões tanto da linguagem, quanto da cognição, bem como de fenômenos cujo tratamento não pode prescindir da consideração nem de um, nem de outro, como é o caso da afasia. Os trabalhos de Coudry e seu grupo têm demostrado isso há mais de trinta anos, em pesquisas que se desenvolveram/desenvolvem no âmbito do IEL-UNICAMP, mas que, para muito além dos prédios do Instituto, alcançam notoriedade nacional e internacional.

Neste ensaio, procurei dar a conhecer a produtividade dos pressupostos da Neurolinguística de tradição discursiva (ND), em especial no que diz respeito à abordagem teórico-metodológica proposta por Coudry e desenvolvida pelos pesquisadores no CCA. De maneira mais pontual, procurei dar visibilidade ao modo como as práticas conduzidas no interior desse Centro podem efetivamente contribuir não apenas para uma intervenção efetiva nos casos de afasia, mas 
também para o refinamento de redes teóricas que, apesar de sofisticadas, nem sempre conseguem alcançar a especificidade dos fenômenos de linguagem.

\section{REFERÊNCIAS}

COLE, M., ENGESTRÖM, Y. A cultural-historical approach to distributed cognition. In SALOMON, G. (Ed.). Distributed cognitions. New York: Cambridge University Press, 1993. p. 1-46

COUDRY, Maria Irma Hadler. Diário de Narciso: avaliação e acompanhamento longitudional de linguagem de sujeitos afasicos de uma perspectiva discursiva. Tese (Doutorado em Linguística). Instituto de Estudos da Linguagem, Universidade Estadual de Campinas, Campinas,1986.

COUDRY, Maria Irma Hadler. Diário de Narciso: discurso e afasia. São Paulo: Martins Fontes, 1988.

COUDRY, Maria Irma Hadler. Diário de Narciso e Neurolinguística Discursiva: 30 anos depois. Cadernos de Estudos Linguísticos, Vol. 60 (2), 2018.

COUDRY, Maria Irma Hadler. Neurolinguística discursiva: afasia e infância, um encontro possível. Projeto (Produtividade em Pesquisa CNPq, Processo n. 311504/2016-7). Conselho Nacional de Desenvolvimento Científico e Tecnológico - CNPq, Brasília, 2016.

COUDRY, Maria Irma Hadler, FREIRE, Fernanda Maria Pereira. Fala e leitura: uma (re)entrada para a escrita. Cadernos de Estudos Linguísticos - (59.3), Campinas, p. 565-579 - set./dez. 2017.

COURTINE, Jean-Jacques. Análise do discurso político: o discurso comunista endereçado aos cristãos. Trad. C. de Campos et, al. São Carlos: EdUFSCar, 2009. (Título original: Quelques problèmes théoriques et méthodologiques em analyse du discours. À propôs du discours communiste adresse aux chrétiens. Langages 62, 1981).

DEBRAY, Régis. Cours de médiologie générale. Paris: Gallimard, 1991.

DUCROT, Oswald. Princípios de semântica linguística: dizer e não dizer. Trad. C. Vogt, R. Ilari. São Paulo: Cultrix, 1977. (Título original: Dire et ne pas dire. Principes de sémantique linguistique, 1972).

FLOR, Nick, HUTCHINS, Edwin. Analyzing distributed cognition in software teams: a case study of team programming during perfective software maintenance. In: Proceedings of the fourth annual workshop on empirical studies of programmers. Norwood, N. J. Anais... Norwood, N. J: Ablex Publishing, 1991. p. 36-59.

FOUCAULT, Michel. Arqueologia do saber. 7. ed. Trad. L. F. B. Neves. Rio de Janeiro: Forense Universitária, 2004. (Título original: L’archéologie du savoir, 1969).

HUTCHINS, Edwin. The technology of team navigation. In: GALEGHER, JOLENE; KRAUT, ROBERT; EGIDO, CARMEN. Intellectual Teamwork: social and technological foundations of cooperative work. Hillsdale, N. J: LEA, 1990. p. 191-220.

HUTCHINS, Edwin. Cognition in the wild. Cambridge, MA: MIT Press, 1995a.

HUTCHINS, Edwin. How a cockpit remembers its speeds. Cognitive Science, n. 19, p. 265-288, 1995 b. 
HUTCHINS, Edwin. Cognitive artifacts. 2002. Disponível em: <http://ato.ms/MITECS/Entry/boster. html>. Acesso em: 11 fev., 2017.

HUTCHINS, Edwin, KLAUSEN, Tove. Distributed Cognition in an Airline Cockpit. In: MIDDLETON, DAVID; ENGESTRON, YRJÖ. Communication and cognition at work. Cambridge: CUP, 1996.

HENRY, Paul. Construções relativas e articulações discursivas. Trad. J. W. Geraldi , C. M. Cruz. Cadernos de Estudos Linguísticos. Campinas: Unicamp-IEL, n. 19, jul./dez., 1990. p. 43-64 (Título original: Contructions relatives e articulations discursive. Langages 35, 1975).

MAINGUENEAU, Dominique. Análise de textos de comunicação. 2. ed. São Paulo: Cortez, 2002. (Título Original: Analyser les textes de communication, 1998).

MaINGUENEAU, Dominique. Discurso literário. São Paulo: Contexto, 2006. (Título original: Le discours littéraire, 2005).

MAINGUENEAU, Dominique. Discurso e análise do discurso. São Paulo: Parábola, 2015. (Título original: Discours et analyse du discours - Introduction, 2014).

MAINGUENEAU, Dominique. Gênese dos discursos. Trad. S. Possenti. Curitiba: Criar Edições, 2005. (Título original: Genèses du discours, 1984).

NORMAN, Donald. Cognitive artifacts. In: CARROLL, John Millar (Org.). Designing Interaction: psychology at the human-computer interaction interface. New York: Cambridge University Press, 1991.

PAVEAU, Anne-Marie. Os pré-discursos: sentido, memória, cognição. Trad. G. Costa, D. Massmann. Campinas: Pontes, 2013. (Título original: Les prédiscours. Sens, mémoire, cognition, 2006).

PÊCHEUX, Michel. Semântica e discurso: uma crítica à afirmação do óbvio. Trad. E. P. Orlandi et. al. Campinas: Editora da Unicamp, 1988. (Título original: Les verités de la Palice. Linguistique, sémantiques, philosophie, 1975).

PÊCHEUX, Michel. O discurso: estrutura e acontecimento. Campinas: Pontes, 1990. (Título original: Discourse: structure or event?, 1983). 